\title{
Livedo Reticularis during Amantadine Treatment
}

\author{
DOROTHY I. VOLLUM, J. D. PARKES, D. DOYLE
}

British Medical fournal, 1971, 2, 627-628

\section{Summary}

Livedo reticularis is a common side effect of treatment with amantadine for Parkinson's disease. Investigation of $\mathbf{4 0}$ such patients suggests that the livedo is a physiological response provoked by depletion of catecholamine stores in peripheral nerve terminals.

Livedo reticularis, a reddish blue network pattern of skin discoloration, is seen as a physiological reaction to cold. Though more common in children, it is frequently present in adults. Livedo, however, also occurs in drug-induced lupus erythematosus and other systemic disorders as a result of an arteritis affecting the dermal vessels. The report of livedo resulting from amantadine treatment of women with Parkinson's disease (Shealy et al., 1970) thus stimulated further study.

\section{Patients and Methods}

The occurrence and extent of livedo reticularis was studied in 40 patients with idiopathic Parkinson's disease during amantadine treatment. There were 19 men and 21 women aged 48 to 73 (mean age 57) who had Parkinson's disease of varying severity. Amantadine hydrochloride dosage was from 100 to $400 \mathrm{mg}$ /day and the period of treatment was from 2 to 12 (mean 11) months. Most patients were also taking anticholinergic drugs and 16 were taking levodopa. Fifty-one non-Parkinsonian hospital inpatients aged 40 to 80 (mean age $63 ; 29$ men and 22 women) were studied as controls.

All the patients were examined after standing for two minutes when they had been in a room at $70^{\circ} \mathrm{F}\left(21^{\circ} \mathrm{C}\right)$ for at least one hour. They were then examined in the lying position to show any effect of posture on livedo. To exclude a drug-induced lupus erythematosus syndrome or related disorder, patients on amantadine were examined for hepatosplenomegaly and lymphadenopathy, and their blood pressure was measured. In a randomly selected group comprising eight of these patients haemoglobin estimation, white blood cell and platelet counts, E.S.R., L.E. cells, antinuclear factor, cryoglobulins, and immunoglobulins were studied. The serum proteins, blood urea, serum aspartate aminotransferase, bilirubin, and alkaline phosphatase levels were also measured. Skin biopsies were done in six patients in whom livedo had developed during amantadine treatment. They were taken from the reddish blue part of the eruption and cut right down to the subcutaneous fat. Several sections were made at various levels in the blocks so the vessels could be examined. To study the responses of the peripheral skin vessels $0.1 \mathrm{ml}$ of adrenaline $(1 \mathrm{mg} / \mathrm{ml}), 0.1 \mathrm{ml}$ of noradrenaline $(2 \mu \mathrm{g} / \mathrm{ml})$, and $0.1 \mathrm{ml}$ of isoprenaline $(1 \mathrm{mg} / \mathrm{ml})$ were injected intradermally in six patients with livedo during amantadine treatment. In two patients $0.05 \mathrm{ml}$ of noradrenaline was injected intradermally $(0.002,0.2$, and $2 \mu \mathrm{g} / \mathrm{ml})$. The maximum diameter of resultant pallor was measured at fixed times following injection (see Chart).

Thirty-two of the 51 control patients not having Parkinson's disease had some degree of livedo. The legs were affected in all

King's College Hospital, London S.E.5

DOROTHY I. VOLLUM, M.R.C.P., D.C.H., Senior Registrar in Dermatology

J. D. PARKES, M.D., M.R.C.P., Senior Registrar in Neurology Pathologist, Institute of Neurological Sciences, Glasgow)
32 , the arms in 16 , and the trunk in six. Livedo was equally common in men and women and was as frequent in the younger patients as in the older ones. Only five patients had noticed this reticulation and none could date its onset. The frequency of livedo in untreated patients with Parkinson's disease was comparable to that in the controls.

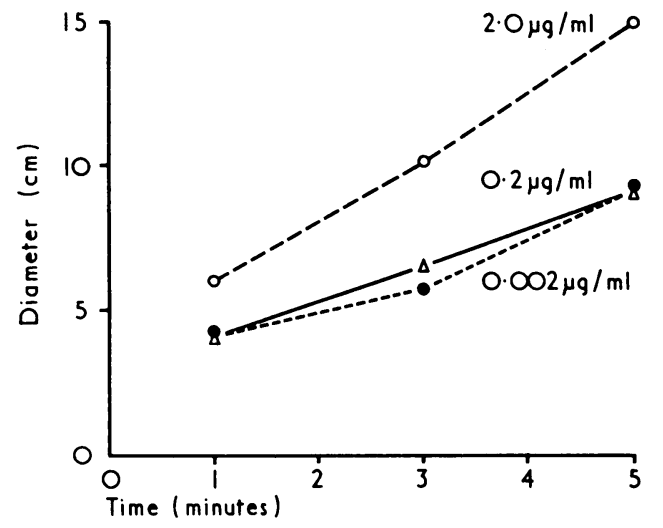

Maximum diameter of the skin pallor produced by noradrenaline against time.

After amantadine treatment livedo was noted in all the 21 women and 15 of the 19 men. Of the 36 patients with livedo, 13 were also taking levodopa. Sixteen commented spontaneously on this discoloration. In some cases livedo was present only on the legs, but in others the arms, buttocks, and sometimes the trunk were involved. In no case was it seen on the face. Then network pattern of livedo was continuous and not broken. It was very prominent during amantadine treatment, being accentuated on the legs after the patient had stood erect for two to three minutes. It became fainter and almost disappeared after lying flat for 15 minutes. Occasionally a faint hyperpigmented pattern persisted, perhaps due to melanin deposition around the areas of stasis. The livedo returned almost at once on standing. Pronounced livedo of considerable extent occurred in patients on $100 \mathrm{mg}$ and on $400 \mathrm{mg}$ of amantadine a day. In three patients in whom amantadine treatment was stopped livedo gradually disappeared over 6 to 12 weeks. Twenty patients with livedo also had some degree of bilateral foot and ankle swelling. This ankle oedema was not seen in the absence of livedo, but the severity of oedema was not related to the severity of livedo. One patient had plaques of erythema on the lower legs which appeared five weeks after beginning amantadine.

None of the patients had hepatosplenomegaly or lymphadenopathy. Their blood pressure was within the normal range. The extensive investigations made in eight patients to exclude an underlying systemic disorder or a lupuserythematosus-like drug-induced syndrome were negative.

Skin biopsies in five patients with livedo provoked by amantadine were normal. In a sixth a small venule was partially occluded by organizing thrombus. There was an associated inflammatory cell infiltrate, mainly lymphocytic, around the blood vessel. There was no other evidence of a vasculitis in this case.

Adrenaline and noradrenaline injections in six patients caused pronounced vasoconstriction with a loss of the livedo pattern and pallor of the surrounding skin. This suggested that 
amantadine did not cause alpha-receptor blockade within the dermal vessels. Intradermal injections of isoprenaline $0.1 \mathrm{ml}$ of $1 \mathrm{mg} / \mathrm{ml}$ caused accentuation of the vascular pattern; however, the response to isoprenaline showed marked variability, and in weaker dilutions a reddening of the network pattern of skin vessels and a pallor of the surrounding skin occurred.

\section{Comment}

Livedo reticularis is a common finding in both control subjects and untreated patients with Parkinson's disease. The blood supply of the skin is through arterioles which each supply a cone-shaped area with a base from 1 to $4 \mathrm{~cm}$ across (Unna, 1896). Where the bases anastomose there is some dilatation of the venules and capillaries with relative stasis giving a cyanotic discoloration. Livedo is accentuated during amantadine treatment, and the diffuse continuous pattern suggests a generalized vascular change of a physiological nature due to a widespread dilatation of the dermal vessels. (A patchy distribution is seen in livedo occurring as a result of underlying arteritic lesions.)

In some patients livedo was accompanied by ankle oedema. This ankle oedema was not associated with any increase in total body water or salt retention (Parkes et al., 1971) and was perhaps due to increased vascular permeability in the cutaneous blood vessels. However, oedema does not commonly accompany either physiological or pathological livedo, though in the latter definite changes in the blood vessels occur.

Amantadine will cause depletion of catecholamine stores in peripheral nerve terminals (Grelak et al., 1970). In normal dosage it has little or no direct action on smooth muscle (Vernier et al., 1969). Thus livedo produced by amantadine treatment may be caused by an effect of this drug on physiologically active substances in nerve terminals of the sympathetic nervous system, though this possibility requires to be further explored. The absence of any evidence of drug-induced systemic disease during amantadine treatment is in keeping with a physiological rather than a pathological cause of livedo.

\section{References}

Grelak, R. P., Clark, R., Stump, J. M., and Vernier, V. G. (1970). Science, $169,203$.

Parkes, J. D. et al. (1971). Lancet In press.

Shealy, C. N., Weeth, J. B., and Mercier, D. (1970). Fournal of the American Medical Association, $212,1522$.

Unna, P. G. (1896). In Histopathology of Diseases of the Skin, translated by N. Walker. Edinburgh, Clay.

Vernier, V. G., et al. (1969). Toxicity and Applied Pharmacology, 15, 642.

\section{MEDICAL MEMORANDA}

\section{Diagnosis of Haemorrhagic Illness}

\author{
A. DAVID GINSBURG, HERMAN A. GODWIN, \\ RICHARD H. ASTER
}

British Medical fournal, 1971, 2, 628-629

Disseminated intravascular coagulation is being diagnosed with increasing frequency in a variety of clinical circumstances. The spectrum of its manifestations is broad, ranging from a rapidly fatal haemorrhagic illness to situations in which the condition is detectable only by laboratory testing. The following case report illustrates difficulties that may be encountered in differentiating this disorder from idiopathic thrombocytopenic purpura. It also emphasizes tr. dramatic response which may be obtained with heparin therapy, the need for gauging the dose correctly, and the hazards that may be associated with the use of this drug.

\section{Case Report}

An 85-year-old woman was admitted to the Boston City Hospital because of rectal bleeding. A full history and physical examination showed the only other significant findings to be the presence of ecchymoses and petechiae over the legs and soft palate. Sixteen months previously severe trauma and operation had been tolerated without excessive bleeding.

Investigations showed haemoglobin $6.6 \mathrm{~g} / 100 \mathrm{ml}$; reticulocyte count $1.7 \%$; and W.B.C. $7,500 / \mathrm{mm}^{3}$ (normal differential). Red cells seemed mildly hypochromic and microcytic. Fragmented red cells

Thorndike Memorial Laboratory and Harvard Medical Service, Boston City Hospital, Boston, Massachusetts

A. DAVID GINSBURG, M.D., F.C.P.(s.A.), Assistant Professor of Medicine, (Present address: Queen's University Medical School, Kingston, Ontario, Canada)

HERMAN A. GOD

Medical School

RICHARD H. ASTER, M.D., Professor of Medicine, (Present address: Milwaukee Blood Center, 763 North 18th Street, Milwaukee, Wisconsin) were not apparent. Platelets appeared severely decreased (6,900/ $\mathrm{mm}^{3}$ ). The bone marrow was cellular, with increased megakaryocytes and absent stainable iron. The plasma fibrinogen level (ammonium sulphate precipitation method) was $420 \mathrm{mg} / 100 \mathrm{ml}$ and the prothrombin time $15 \cdot 5: 13 \cdot 0$ seconds.

In view of a negative history, physical examination, and further laboratory investigations idiopathic thrombocytopenic purpura was diagnosed. Therapy with prednisone $40 \mathrm{mg}$ by mouth daily was instituted. The response is shown in the Chart. Steroid administration on several occasions was associated with a rise in the platelet count, while a reduction in the dose was rapidly followed by a fall in platelet levels. Splenectomy was therefore considered and her coagulation status was re-evaluated. Plasma fibrinogen concentration was found to be reduced to $40 \mathrm{mg} / 100 \mathrm{ml}$ (both Ellis-Stranski and ammonium sulphate precipitation techniques). The prothrombin time was $16 \cdot 2: 12 \cdot 8$ seconds and the thrombin time $22 \cdot 6: 15 \cdot 6$ seconds. Partial thromboplastin time was 39:39 seconds. The factor VIII level (one-stage technique) was $200 \%$ of normal. Cryofibrinogen was present and a few fragmented red blood cells were noted on the peripheral smear.

Disseminated intravascular coagulation was diagnosed. Prednisone $40 \mathrm{mg}$ daily was continued and heparin $40 \mathrm{mg}$ intravenously every six hours was begun with little effect. The heparin dose was therefore increased to $60 \mathrm{mg}$ every six hours. There was then a prompt increase in platelet and fibrinogen levels, with disappearance of detectable cryofibrinogen. On the third day at the higher heparin dose the patient bled spontaneously into her left thigh. Heparin was discontinued, and within 24 hours the fibrinogen concentration had fallen from 165 to $30 \mathrm{mg} / 100 \mathrm{ml}$, and the platelet count from 70,000 to $42,000 / \mathrm{mm}^{2}$. Cryofibrinogen reappeared. Heparin therapy was reinstituted. Within 24 hours fibrinogen rose to $270 \mathrm{mg} / 100 \mathrm{ml}$ and platelets to 62,000 $\mathrm{mm}^{3}$. Two days later bleeding into the thigh and flank recurred. Heparin was again discontinued, and both the platelet count and the fibrinogen again decreased.

A series of complications then supervened, including abscess formation in the thigh, Gram-negative septicaemia and shock, myocardial infarction, probably secondary to hypotension, congestive heart failure, ill-defined liver functional derangement, and mild acute tubular necrosis. Without apparent explanation platelets and fibrinogen then steadily increased to levels of $180,000 / \mathrm{mm}^{3}$ and $500 \mathrm{mg} / 100 \mathrm{ml}$ respectively (not shown in Chart). Thrombin time was 8.4:7.4 seconds, prothrombin time 12.5:12.5 seconds, and cryofibrinogen was absent. The patient appeared to be improving clinically and she was allowed up. Twenty-seven days after the heparin was discontinued, however, she died suddenly and for no apparent reason. Necropsy 